\title{
Use of Metaphors in Psychoeducation for Depression and Its Relationship With Autistic Traits*
}

\author{
Sawako Nagaoka, Kenichi Asano, Eiji Shimizu \\ Chiba University Graduate School of Medicine, Chiba, Japan
}

\begin{abstract}
The impact of metaphors employed in psychoeducation for depression on people with a tendency for autism spectrum disorders (ASD) was investigated. Japanese undergraduate students ( $N=146,41$ males and 105 females, mean age $=19.45 \pm 2.05$ ) were randomly assigned to a metaphor, or a control group. They rated their perceived impressions of a psychoeducation experience using a questionnaire and also completed the Autism Spectrum Quotient instrument (AQ). Exploratory factor analysis of questionnaire responses identified three factors: Subscale 1: "Depth of understanding" ( 8 items), Subscale 2: "Positive feelings toward the contents" (6 items) and Subscale 3: "New perspective" ( 2 items). In order to examine how AQ level and metaphor presence affected impressions of psychoeducation, we conducted two-factor ANOVA with AQ (High/Low) and metaphor (With/Without) as independent variables. Results of multiple comparisons conducted on subscale scores indicated that the simple main effect of metaphor presencefor "Positive feelings toward the contents" remained significant in the high-AQ group. This suggests that when metaphors are used in psychoeducation for people with high autistic tendencies, they are more likely to have positive impressions about depression including the feeling of familiarity with depression, and feeling hopeful about psychoeducation. It was concluded that metaphors in psychoeducation might help people with autistic tendencies to build a positive perception of the depression at the state of treatment.
\end{abstract}

Keywords: psychoeducation, metaphors, autism spectrum, depression

\section{Introduction}

Psychoeducation is a process by which clinicians teach their patients about the mental illness with which they have been diagnosed. Psychoeducation is an important part of clinical care for mental illness, regardless of the psychotherapeutic orientation. In many cases, it is provided at the beginning of psychotherapy, when clinical professionals need to ensure spending sufficient time with a patient and his or her family members in explaining the nature of the mental illness, as well as treatment options. Since patients are often unfamiliar with mental disorders, or may have misconceptions about them, psychoeducation is a very important process in facilitating accurate information for the patient and family, thereby deepening their understanding of the condition, and increase their motivation to pursue treatment (McFarlane, Dixon, Lukens, \& Lucksted, 2003; Wright, Basco, \& Thase, 2006).

\footnotetext{
*Acknowledgements: This work was supported by JSPS KAKENHI Grant Number 10633315.

Sawako Nagaoka, Ph.D., Department of Cognitive Behavior Physiology, Chiba University Graduate School of Medicine. Kenichi Asano, Ph.D., Research Center for Child Mental Development, Chiba University.

Eiji Shimizu, M.D., Ph.D., Department of Cognitive Behavior Physiology, Chiba University Graduate School of Medicine.
} 
Metaphors are commonly used during psychoeducation in different psychotherapy orientations (March \& Benton, 2006; Kopp, 1995; Zayfert \& Becker, 2006). The use of metaphors by therapists has been shown to have various beneficial effects (Stott, Mansell, Salkovskis, Lavender, \& Cartwright-Hatton, 2010). Metaphors are used to replace unfamiliar terminology and technical characterization of symptoms with familiar everyday experiences. As a result, patients and family members are more likely to easily understand and remember the information that was provided. Recently, Cognitive Behavioural Therapy (CBT) oriented clinicians have embraced the use of metaphor in their practice (Blenkiron, 2010; Stallard, 2002). One of the aims of CBT is to understand their selves and the world more objectively. Metaphor will therefore help it to be the powerful (Stott et al., 2010). Being able to skilfully use metaphors is now considered to be a very important part of delivering psychotherapy.

\section{Autism Spectrumand Metaphor Comprehension}

Previous research has indicated that understanding metaphors is difficult for people with autism. Rundlad and Annaz (2010) compared the ability of children with autism ranging in age from 5-11 years on their comprehension of metaphor and metonymy against typically developing children of the same ages. They found that children with autism showed uniformly impaired metaphor comprehension relative to both their age and broader verbal abilities. Earlier research by Minshew, Goldstein, and Siegel (1995) tested high-functioning autistic individuals against typically developing individuals of similar IQ. The autistic individuals did as well as the controls on procedural language tests, but scored significantly lower on tests of figurative language, including metaphor. MacKay and Shaw (2004) reported similar findings for figurative language deficits in children with autistic spectrum disorder (ASD). The term ASD refers to a range of conditions such as Asperger's syndrome, which are related to the core disorder of autism. These disorders are characterized by impaired social interactions, communication, and imagination. However, MacKay and Shaw's (2004) study examined hyperbole, irony, and metonymy, and did not investigate metaphor specifically. To our knowledge, no previous studies have investigated the relationship between ASD and metaphor.

Given that metaphors are generally beneficial when used as part of psychoeducation, the finding that people with autism and ASD have more difficulty interpreting figurative language suggest that they would have more difficulty benefiting from psychoeducational interventions. This would also mean that metaphorical language should be avoided when administering psychoeducation to individuals with autism or ASD.

\section{Depression and Autism}

Depression is the most common comorbidity of people on the autistic spectrum. Lugnegård, Hallerbäck, and Gillberg (2011) found that $70 \%$ of 26 men and 28 women (mean age 27 years) with a clinical diagnosis of Asperger syndrome had experienced at least one episode of major depression, and $50 \%$ had suffered from recurrent depressive episodes. Sterling, Dawson, Estes, and Greenson (2008) reported that 20 participants out of 46 adults with ASD (43\%) showed signs of depressive symptoms. Clearly, young adults with autism spectrum disorders are at high risk for depression.

The diagnosis of Pervasive Developmental Disorder (PDD), including ASD is generally made during childhood. However, people with high-functioning autism (ASD) are more likely to grow into adults without being diagnosed with ASD when younger. It is not rare for people to be diagnosed with ASD only after they develop clinical depression and anxiety disorders. These mood disorders are often triggered by stressful situations such as school, or work-related changes in their environment, or interpersonal relationships. Comorbidity of ASD 
and depression is a serious condition. Moreover, it is difficult to treat the depression in such patients. Therefore, useful therapeutic strategies for treating comorbidity of ASD and depression are needed in clinical settings.

As described above, people with autism and ASD are generally regarded as having difficulties in understanding metaphoric expressions. However, the effects of metaphorsare not only related to comprehension. Metaphors have been used in different types of psychotherapy. The purpose of this study was to explore the effect of metaphors on people with autistic traits, in order to develop psychoeducation programs for people with depression.

\section{Materials and Methods}

\section{Participants}

Japanese undergraduate students $(N=149)$ participated in this study. Approval of Research Ethics Committee of the Chiba University was obtained before the study was conducted and all participants were given verbal and written assurances of confidentiality and anonymity of their responses. Prior to the commencement of the study, all participants provided their written informed consent after receiving a full explanation of the nature of the study and potential risks and benefits of participation. Participation was completely voluntary, and participants were informed that they could cease participation at any time. Data of three students who did not provide informed consent, or gave largely incomplete responses were excluded from the final analysis. The final sample consisted of 41 men and 105 women with an age range of 18 to 27 years (Mean age $=19.45$ years, $S D=3.45$ ).

\section{Psychoeducational Material}

We developed psychoeducational explanations of depression with and without the use of metaphors. Common sentences used to describe metaphors were identified by interviewing clinical psychologists and psychiatrists. The wording of the sentences was based on popular Japanese books on psychoeducation (Shimizu, 2010; Ono, Community Mental Health, \& Welfare Bonding Organization, 2011), Internet websites on depression (EACH MIND MATTERS, 2014; UT Counselling and Mental Health Centre, 2014), and Japanese translations of the Fourth Edition of the Diagnostic and Statistical Manual of Mental Disorders (DSM-IV: American Psychological Association, 1996). We used three types of psychoeducation including "Recovery Process from Depression", "Depression and Selective Attention" and "Depression and Cognitive-Perceptual Narrowing". After developing psychoeducational materials, 10 clinical psychologists and 2 psychiatrists reviewed the content of sentences in the educational material and confirmed the validity of their content.

Participants were randomly divided into two groups. One group was presented with stimulus sentences with metaphors (M-group) and the other group was presented with stimulus sentences without metaphors (C-group). Both groups received the stimulus sentences in the context of psychoeducation (see Appendix 1).

\section{Questionnaires}

Each participant completed two Japanese language questionnaires. The first questionnaire assessed their impressions regarding the effectiveness of psychoeducation for depression that was specially developed for this study. The second questionnaire was the Autism-Spectrum Quotient (Baron-Cohen, Wheelwright, Skinner, Martin, \& Clubley, 2001).

\section{Impression Regarding the Psychoeducation Scale (IRPS)}

We originally developed a 16-item questionnaire inquiring participants' impressions regarding the 
psychoeducation to assess their impressions about the psychoeducational material. This questionnaire consisted of 16 short statements including "Easy to imagine" and "Got a new perspective". Participants were asked to indicate the degree to which they agreed with each statement on a 7-point scale. Appendix 2 shows all the questionnaire items. Some of the items were chosen to explore the effects of metaphors based on Stott et al. (2010) and Marschark et al. (1983). In scoring this questionnaire, raw scores for negatively worded items were reversed (Item 13: Discombobulated).

The Autism-Spectrum Quotient (AQ) is a 50-item self-report questionnaire that assesses autistic traits. The AQ has been shown to have reasonable face and construct validity (Baron-Cohen et al., 2001). Wakabayashi, Tojo, Baron-Cohen, and Wheelwright (2004) adapted and standardized this questionnaire for the Japanese population, and confirmed that the Japanese version of the questionnaire was equivalent in terms of reliability and validity to the UK version. Specific statements for which autistic responses would be true are given a score of 1 if they were marked "Definitely true" or "Slightly true", and a score of 0 if marked "Untrue", or "Definitely untrue". In scoring this questionnaire, the scores for negatively worded items are reversed, in accordance with the Japanese AQ (Wakabayashi et al., 2004). Thus, the range of possible scores in this questionnaire is $0-50$, with higher scores indicating the presence of more autistic traits. Furthermore, it has been suggested that a cut-off point of 33 or above correctly identifies people with autistic traits in the general population. Participants responded to the 50 questionnaire items on a 4-point scale ranging from 1 ("Definitely untrue") to 4 ("Definitely true").

\section{Statistical Analysis}

We conducted exploratory factor analysis on participants' responses to the questionnaire inquiring about impressions regarding psychoeducation. All participants that were randomly allocated to the Metaphor $(\mathrm{M})$ or the Control (C) group were divided into the high-AQ group (AQ scores higher than the median), or the low-AQ group (AQ scores lower than the median). A two-way $(2 \times 2)$ analysis of variance (ANOVA) was conducted to analyse for metaphor and AQ level (Metaphor/Control $\times$ High-AQ/Low-AQ). All analyses were performed with SPSS version 20.0.0 for Windows.

\section{Results and Discussion}

\section{Developing Impression Regarding Psychoeducation Scale}

After calculating the total score of Impression Regarding the Psychoeducation Scale (IRPS), we conducted exploratory factor analysis (maximum-likelihood estimation, promax rotation). We selected a three-factor structure was considered and one item was deleted as valid. 15 items with factor loadings of 0.60 or higher and created a scale to measure impression of psychoeducation.

Table 1 shows the results of the factor analysis and the correlations between factors. We selected 15 items with factor loadings of 0.60 or higher and created a scale to measure impression of psychoeducation. The first factor was named "Depth of understanding", because eight items indicating the level of understating of the disorder such as "Easy to understand" and "Easy to imagine" were classified into this factor. The second factor was named "Positive feelings toward the contents", because six items indicating positive emotions about the disorder, such as "Looks hopeful" and "Felt warm" were classified into this factor. The third factor was named "New perspective" because the two items "Got new knowledge" and "Got a new perspective" were classified into this factor. As shown in Table 1, each factor had sufficient internal consistency (Cronbach's alpha 
coefficient was 0.91 for Factor 1, 0.90 Factor 2, and 0.91 for Factor 3. We named the newly developed questionnaire, "Impressions Regarding Psychoeducation Scale (IRPS)".

Table 1

Results of Factor Analyzing Impressions Regarding Psychoeducation

\begin{tabular}{|c|c|c|c|c|c|c|c|}
\hline & Item & $\mathrm{F} 1$ & $\mathrm{~F} 2$ & F3 & $M$ & $S D$ & $\alpha$ \\
\hline \multicolumn{8}{|c|}{$<$ Factor 1: Depth of understanding $>$} \\
\hline 1 & Easy to follow & 0.943 & 0.037 & 0.091 & 5.52 & 0.93 & \multirow{7}{*}{0.91} \\
\hline 2 & Easy to understood & 0.910 & 0.000 & 0.020 & 5.54 & 0.97 & \\
\hline 3 & Understand the important point & 0.793 & 0.046 & 0.000 & 5.47 & 1.07 & \\
\hline 4 & Anyone could understand this caption & 0.697 & 0.085 & 0.050 & 5.00 & 1.11 & \\
\hline 5 & Discombobulated & 0.682 & -0.226 & -0.067 & 5.77 & 1.08 & \\
\hline 6 & Easy to imagine & 0.659 & 0.138 & 0.142 & 5.15 & 1.09 & \\
\hline 7 & Fulfilled & 0.623 & 0.048 & 0.065 & 5.31 & 1.09 & \\
\hline \multicolumn{8}{|c|}{$<$ Factor 2: Positive feelings toward the contents $>$} \\
\hline 8 & Liked the captions & 0.000 & 0.930 & -0.120 & 3.78 & 1.28 & \multirow{6}{*}{0.90} \\
\hline 9 & Looked hopeful & 0.158 & 0.913 & 0.079 & 3.72 & 1.32 & \\
\hline 10 & Felt familiar to me & 0.011 & 0.800 & -0.197 & 4.23 & 1.41 & \\
\hline 11 & Felt warm & -0.108 & 0.766 & 0.091 & 3.68 & 1.36 & \\
\hline 12 & Interesting & -0.061 & 0.691 & 0.225 & 4.57 & 1.20 & \\
\hline 13 & Intimate style & 0.287 & 0.637 & 0.058 & 4.45 & 1.28 & \\
\hline \multicolumn{8}{|c|}{$<$ Factor 3: New perspective $>$} \\
\hline 14 & Got a new knowledge & 0.017 & -0.151 & 1.078 & 5.15 & 1.23 & \multirow{2}{*}{0.91} \\
\hline 15 & Got a new perspective & 0.031 & 0.139 & 0.781 & 4.64 & 1.28 & \\
\hline \multicolumn{2}{|c|}{ Internal correlations } & F1 & $\mathrm{F} 2$ & \multicolumn{4}{|l|}{ F3 } \\
\hline & F1 & - & & & & & \\
\hline & F2 & 0.631 & - & & & & \\
\hline & F3 & 0.584 & 0.625 & - & & & \\
\hline
\end{tabular}

Note. Scores of Item 5 were reversed.

\section{Result of ANOVA}

We conducted a two-factor ANOVA with AQ level and the presence of metaphor as independent variables and IRPS score as the dependent variable. Mean and $S D$ about AQ values of each group are as shown in Table 2. Wakabayashi et al. (2004) suggested an AQ cut-off point of 33 or higher; the sample of university students in the same study had a mean of 20.7 points. Therefore, we defined the scores of the low-AQ group as sufficiently low (M-group: 16.76, C-group: 17.85) and scores of high-AQ group as sufficiently high (M-group $=27.71, \mathrm{C}$-group $=28.09)$. High-AQ group include nine participants exceeded the cut-off points $(\mathrm{M}$-group $=5$, C-group $=4$ ).

Table 3 indicates average scores and standard deviations of the IRPS, as well as the results of the analyses of variance for the four groups, classified by AQ level and metaphor presence. Average scores of IRPS score for each group and the results of multiple comparisons are indicated in Figure 1.

The ANOVA indicated that the main effect by AQ level was significant for Subscale 1, depth of understanding $(F(1,142)=6.39, p<0.05)$. The main effect by metaphor presence was significant for Subscale 2, positive feelings toward the contents and Subscale 3, new perspective $(\mathrm{F} 2: F(1,142)=7.91, p<0.001$; F3: $F(1,142)=8.71, p=0.01)$. 
Table 2

Means and SDs of (Low/High-AQ $\times$ Metaphor/Control)

\begin{tabular}{llllll}
\hline & \multicolumn{2}{c}{ Low-AQ } & \multicolumn{2}{c}{ High-AQ } \\
\cline { 2 - 6 } & & Metaphor $(n=33)$ & Control $(n=41)$ & Metaphor $(n=28)$ & Control $(n=44)$ \\
\hline \multirow{2}{*}{ AQ } & Mean & 16.76 & 17.85 & 27.71 & 28.09 \\
& $S D$ & 3.45 & 3.65 & 3.74 & 4.15 \\
\hline
\end{tabular}

Table 3

Results of Analysis of Variance (Low/High-AQ $\times$ Metaphor/Control)

\begin{tabular}{|c|c|c|c|c|c|c|c|c|}
\hline & & \multicolumn{2}{|c|}{ Low-AQ $(n=74)$} & \multicolumn{2}{|c|}{ High-AQ $(n=72)$} & \multicolumn{2}{|c|}{ Main effect } & \multirow{2}{*}{ - Interaction } \\
\hline & & $\mathrm{M}(n=33)$ & $\mathrm{C}(n=41)$ & $\mathrm{M}(n=28)$ & $\mathrm{C}(n=44)$ & $\mathrm{AQ}$ & Metaphor & \\
\hline Subscale 1 & $\begin{array}{l}\text { Depth of } \\
\text { understanding }\end{array}$ & $\begin{array}{l}5.68 \\
(0.78)\end{array}$ & $\begin{array}{l}5.49 \\
(0.82)\end{array}$ & $\begin{array}{l}5.31 \\
(0.71)\end{array}$ & $\begin{array}{l}5.15 \\
(0.94)\end{array}$ & $\begin{array}{c}6.39^{*} \\
{[0.04]}\end{array}$ & $\begin{array}{l}1.51 \\
(0.01)\end{array}$ & $\begin{array}{l}0.02 \\
{[0.00]}\end{array}$ \\
\hline Subscale 2 & $\begin{array}{l}\text { Positive feeling } \\
\text { toward the } \\
\text { contents }\end{array}$ & $\begin{array}{l}5.30 \\
(1.16)\end{array}$ & $\begin{array}{l}4.80 \\
(1.13)\end{array}$ & $\begin{array}{l}5.09 \\
(1.08)\end{array}$ & $\begin{array}{l}4.47 \\
(1.32)\end{array}$ & $\begin{array}{l}1.74 \\
{[0.01]}\end{array}$ & $\begin{array}{c}7.91^{* *} \\
{[0.05]}\end{array}$ & $\begin{array}{l}0.09 \\
{[0.00]}\end{array}$ \\
\hline Subscale 3 & New perspective & $\begin{array}{l}5.29 \\
(1.25) \\
\end{array}$ & $\begin{array}{l}4.91 \\
(1.09) \\
\end{array}$ & $\begin{array}{l}5.17 \\
(0.94) \\
\end{array}$ & $\begin{array}{l}4.41 \\
(1.26)\end{array}$ & $\begin{array}{l}2.64 \\
{[0.02]}\end{array}$ & $\begin{array}{l}8.71^{* *} \\
{[0.06]}\end{array}$ & $\begin{array}{c}0.9 \\
{[0.01]}\end{array}$ \\
\hline
\end{tabular}

Notes. ${ }^{* *} p<0.01, \stackrel{*}{p}<0.05 ;()=$ standard deviations, []$=$ effect size.

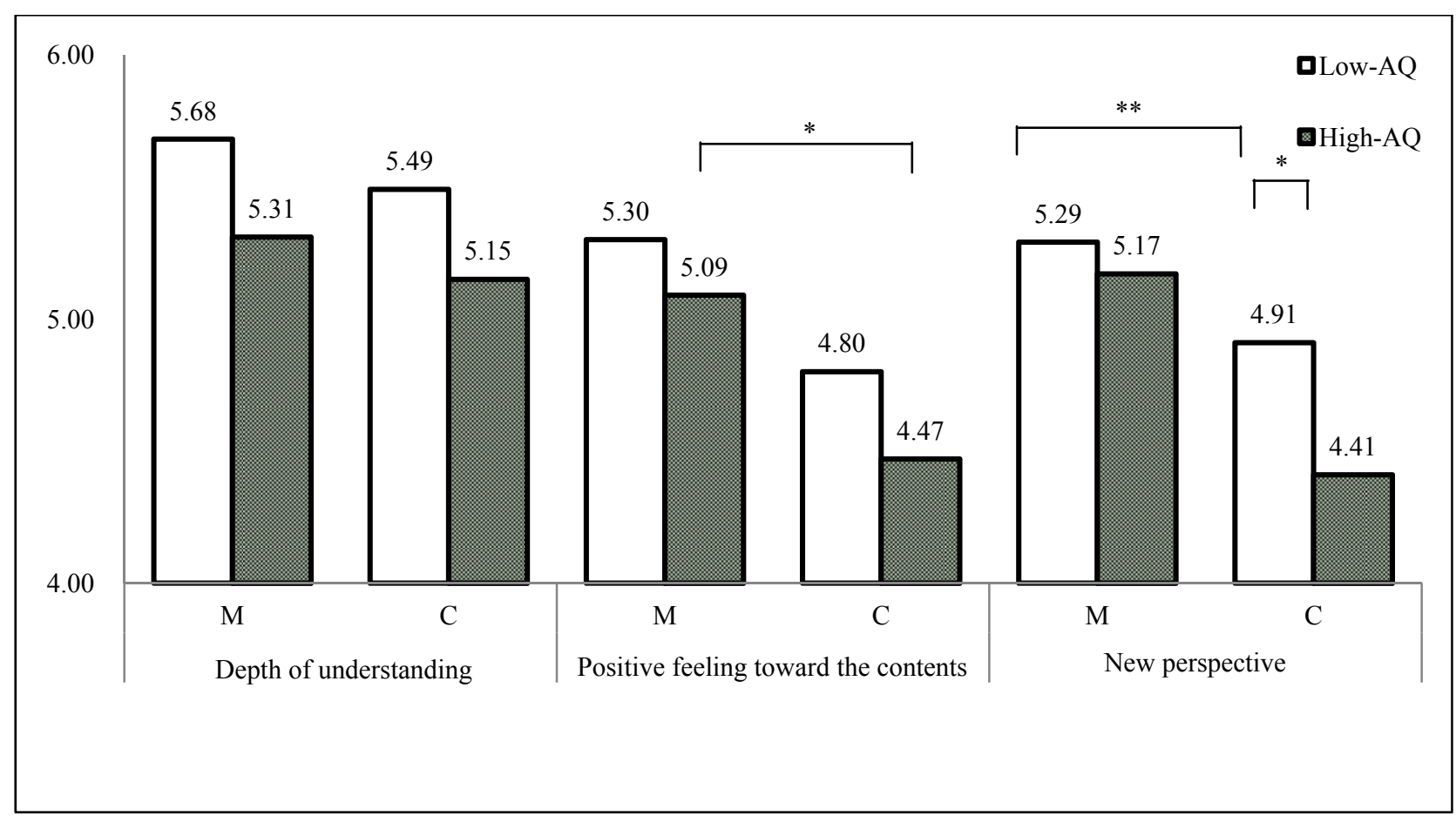

Figure 1. Mean impression assessment scores for each group and results of a multiple comparison (M: Metaphor group, C: Control group).

In order to examine the differences between the average values in more detail, we conducted multiple comparisons by subscale for each group. Results indicated that for Subscale 2, the simple main effect by metaphor presence remained significant at the $5 \%$ level $(F(1,142)=4.67, p<0.05)$ in the high-AQ group. For Subscale 3 , there were significant differences $(F(1,142)=7.35, p<0.01)$ by AQ level only for the $\mathrm{C}$ group and the simple main effect by metaphor presence was significant $(F(1,142)=7.35, p<0.01)$ only for the high-AQ group. In all subscales, the low-AQ group had higher scores than the high-AQ group. 
This study was conducted with undergraduates to investigate the effects of metaphors on psychoeducation for people with autistic tendencies. We assessed participants' impressions regarding psychoeducation for depression with and without the use of metaphors.

In order to examine how AQ level and metaphor presence affected impressions of psychoeducation, we conducted two-factor ANOVA with AQ (High/Low) and metaphor (With/Without) as independent variables and IRPS score as the dependent variable.

Results of multiple comparisons conducted on subscale scores indicated that the simple main effect of the presence of metaphors on "Positive feelings toward the contents" remained significant in the high-AQ group. This suggested that when metaphors are used in psychoeducation for people with high autistic tendencies, they are more likely to have positive impressions about depression including the feeling of familiarity with depression, feeling hopeful, and feeling that they gained new knowledge about psychoeducation. Moreover, people with high autistic tendencies responded more favourably toward psychoeducation with metaphors, than for psychoeducation without metaphors. Based on the above results, we concluded that the use of metaphoric expressions might help people with high autistic spectrum traits to appreciate psychoeducation for depression positively. Using metaphors made high AQ participants feel more hopeful about depression.

In general, people with high ASD tendencies are more likely to pay attention to details of language and information. If they get distracted by such details during a psychoeducation course, they would be less likely to understand, or be convinced by the information provided in the course. As a result, they might be unable to have positive impressions about explanations regarding their disorder. However, our results suggested that the addition of metaphoric explanations to psychoeducation gives a positive impression of the information. We believe that this finding would be useful for the treatment of depression in people with ASD.

One limitation of this study was that it used a non-clinical participant sample. This point is a significant limitation on the generalizability of our results. It is suggested that future research be conducted with ASD patients. Nevertheless, the results of this study have important implications in developing more effective psychoeducation for autistic people. Furthermore, previous studies have indicated that people with low AQ could easily understand psychoeducation. In clinical settings, however, metaphors are used to compare with things that are familiar to the patient. It is suggested that future studies should be conducted to accumulate concrete metaphors used in clinical settings to investigate more effective psychoeducation methods for people with ASD.

\section{Conclusions}

In general, depression in people with autistic tendencies is difficult to treat. The current study indicated that metaphors used in psychoeducation might help people with autistic tendencies to build a positive perception of depression and its treatment.

\section{References}

American Psychiatric Association. (1996). Takahashi, S., Ono, Y., \& Someya, T. (Trans.). Diagnostic and statistical manual of mental disorders (4th ed.). City of Publication: Igaku-Shoin Ltd.

Baron-Cohen, S., Wheelwright, S., Skinner, R., Martin, J., \& Clubley, E. (2001). The Autism-spectrum quotient (AQ): Evidence from Asperger syndrome/high-function in gautism, males and females, scientists and mathematicians. Journal of Autism Developmental Disorder, 31(1), 5-17.

Blenkiron, P. (2010). Stories and analogies in cognitive behaviour therapy. Chichester, UK: Wiley-Blackwell. 
EACH MIND MATTERS. (2014). Making depression into a Metaphor: How the Japanese handle depression. California's Mental Health Movement. Retrieved 6 November, 2014, from http://www.eachmindmatters.org/blog/making-depression -metaphor-japanese-handle-depression/

Eiji, Shimizu. (2010). Ninchikoudouryouhou no subete ga wakaru hon (The book of all about the Cognitive behavioral therapy). Koudan-Sya. (in Japanese)

Kopp, R. R. (1995). Metaphor therapy: Using client-generated metaphors in psychotherapy. London: Brunner-Routledge.

Lugnegård, T., Hallerbäck, M. U., \& Gillberg, C. (2011). Psychiatric comorbidity in young adults with a clinical diagnosis of Asperger syndrome. Research in Developmental Disabilities, 32(5), 1910-1917.

Marschark, M., Katz, A. N., \& Paivio, A. (1983). Dimensions of metaphor. Journal of Psycholinguistic Research, 12(1), 17-40.

McFarlane, W. R., Dixon, L., Lukens, E., \& Lucksted, A. (2003). Family psychoeducation and schizophrenia: A review of the literature. Journal of Marital and Family Therapy, 29(2), 223-245.

MacKay, G., \& Shaw, A. (2004). A comparative study of figurative language in children with autistic spectrum disorders. Child Language Teaching and Therapy, 20(1), 13-32.

March, J. S., \& Benton, C. M. (2006). Talking back to OCD: The program that helps kids and teens say "No way"-And parents say "Way to go". Guilford Press.

Minshew, N. J., Goldstein, G., \& Siegel, D. J. (1995). Speech and language in high-functioning autistic individuals. Neuropsychology, 9(2), 255-261.

Ono, Y., Community Mental Health, \& Welfare Bonding Organization. (2011). Utsu-byou no hito noKimochi ga wakaru hon (The book about feeling of people with depression). Koudan-Sya. (in Japanese)

Rundblad, G., \& Annaz, D. (2010). The atypical development of metaphor and metonymy comprehension in children with autism. Autism, 14(1), 29-46.

Shimizu, E. (2010). Ninchikoudouryouhou no subete ga wakaru hon (The book of all about the cognitive behavioral therapy). Koudan-Sya. (in Japanese)

Stallard, P. (2002). Cognitive behaviour therapy with children and adolescents: A selective review of key issues. Behavioural and Cognitive Psychotherapy, 30(3), 321-333.

Sterling, L., Dawson, G., Estes, A., \& Greenson, J. (2008). Characteristics associated with presence of depressive symptoms in adults with autism spectrum disorder. Journal of Autism and Developmental Disorders, 38(6), 1011-1018.

Stott, R., Mansell, W., Salkovskis, P., Lavender, A., \& Cartwright-Hatton, S. (2010). Oxford guide to metaphors in CBT: Building cognitive bridges. Oxford: Oxford University Press.

UT Counselling and Mental Health Centre. (2014). Depression. The University of Texas. Retrieved 6 November, 2014, from http://cmhc.utexas.edu/depression.html

Wakabayashi, A., Tojo, Y., Baron-Cohen, S., \& Wheelwright, S. (2004). The Autism-Spectrum Quotient (AQ) Japanese version: Evidence from high-functioning clinical group and normal adults. Shinrigakukenkyu: The Japanese Journal of Psychology, 75(1), 78-84.

Wiig, E. H., \& Secord, W. (1985). Test of language competence. San Antonio, TX: Psychological Corporation.

Wright, J. W., Basco, M. R., \& Thase, M. E. (2006). Learning cognitive-behavior therapy: An illustrated guide. Arlington, VA: American Psychiatric Publishing.

Zayfert, C., \& Becker, C. B. (2006). Cognitive-behavioral therapy for PTSD: A case formulation approach-guides to individualized evidence-based treatment (pp. 59-60). Guilford Press. 


\section{Appendix 1}

We showed Paragraphs 1 to 3 to the metaphor group and asked participants to give their impressions of psychoeducation using items such as "Easy to imagine" and "Got a new perspective", among others. We showed Paragraphs 1 and 2 to the control groups, but did not show Paragraph 3, which included the use of a metaphor in the explanation. Then, we asked participants to give their impressions of psychoeducation.

\section{Psychoeducational material}

[1] How to communicate with people who are depressed: "Communicate as if they have a high fever"

Depression is a disorder accompanied by a continued state of feeling down, anxiety, irritation, and loss of appetite. As one's depression state continues, he or she increasingly uses the words such as "hard" or "painful". Family members who are around them also feel strongly distressed.

When your family member is suddenly diagnosed with depression and he or she is in a depressed state, you may impatiently feel "Maybe I can take him (or her) out for a change". However, forcefully taking out the person who is suffering from depression can be counterproductive. The most important point in the treatment of depression is taking enough rest and taking medications regularly as advised by the doctor. It is important for family members to be calm and look after the person instead of giving suggestions and trying to make him or her change.

When therapists explain how to respond to people with depression to family members, they can use a metaphor and say, "Communicate as if he (or she) has a high fever". When people have a high fever, they increasingly use the words such as "hard" or "painful". Forcefully going out during a high fever worsens the condition. It is most important for the person with depression and his or her family members to patiently wait for a recovery as if they look after someone with a high fever.

[2] Depression and selective attention

1. People with depressive illnesses suffer continuously from depressive feelings, anxiety, and anorexia, among others. People with depressive illnesses cannot help paying attention to various negative things and comparing themselves with what they were before getting the depressive illness.

2. The condition in which people cannot help but seek out things that worry them is called "selective attention". People suffering from depression pay selective attention to negative aspects of life and become sensitive to "what they cannot do" or "things that has gotten worse for them" comparing themselves to what they were when they were healthy. As a result they get more and more depressed. In order to get out of this cycle, people should first of all notice take note of the selectivity of their attention and then try to expand the scope of their attention.

3. It is possible to direct selective attention not only to negative things, but also to positive and likeable things. For example, it has been demonstrated that people can find a person they like, even in a crowd. When a person desires to have a bag for example, they cannot help unconsciously attending to the bag section in shops. In order terminate selective attention to negative things, it is necessary to notice that a person can also pay selective attention to positive things, and try to expand the range of their attention.

[3] Depression and constriction of the psychological visual field

1. When people suffer from serious depressive illnesses, they sometimes fall into a condition of "psychological visual field constriction". Visual field constriction is the state in which the visual field becomes narrow.

2. Psychological visual field constriction is a state in which symptom of visual field constriction appears mentally. When a person cannot see good and enjoyable things, or cannot notice surrounding people who would help them, their choices of ideas and behaviours become severely restricted. Normal life becomes hard for such people and sometimes they even come to believe that they have to die in order to escape their distress. When people get into this condition, it is important not to become impatient 
in attempting to solve their problems, to keep calm, and wait for help and recovery.

3. The state of psychological visual field constriction is compared to the state of being in a tunnel. Surrounded by total darkness, alone, being scared, people tend to misunderstand and think that the choice of committing a suicide is the only solution. However, there are many other solutions. When people are in a state of psychological visual field constriction, it is important not to force themselves out of the tunnel in a hurry, to keep calm and wait for recovery, or for someone to come with a light.

\section{Appendix 2}

\section{Items for evaluating psychoeducational material}

All participants were shown the sentences and asked to indicate the degree to which they agreed with each statement on a 7-point scale.

\begin{tabular}{|c|c|c|c|c|c|c|c|c|}
\hline \multirow[b]{2}{*}{1} & \multirow[b]{2}{*}{ Easy to follow } & \multicolumn{4}{|c|}{ Completely disagree } & \multicolumn{3}{|c|}{ Completely agree } \\
\hline & & 1 & 2 & 3 & 4 & 5 & 6 & 7 \\
\hline 2 & Easy to understand & 1 & 2 & 3 & 4 & 5 & 6 & 7 \\
\hline 3 & Understood the important point & 1 & 2 & 3 & 4 & 5 & 6 & 7 \\
\hline 4 & Anyone could understand this caption & 1 & 2 & 3 & 4 & 5 & 6 & 7 \\
\hline 5 & Discombobulated $※$ & 1 & 2 & 3 & 4 & 5 & 6 & 7 \\
\hline 6 & Easy to imagine & 1 & 2 & 3 & 4 & 5 & 6 & 7 \\
\hline 7 & Satisfied & 1 & 2 & 3 & 4 & 5 & 6 & 7 \\
\hline 8 & Liked the captions & 1 & 2 & 3 & 4 & 5 & 6 & 7 \\
\hline 9 & Looked hopeful & 1 & 2 & 3 & 4 & 5 & 6 & 7 \\
\hline 10 & Felt familiar to me & 1 & 2 & 3 & 4 & 5 & 6 & 7 \\
\hline 11 & Felt warm & 1 & 2 & 3 & 4 & 5 & 6 & 7 \\
\hline 12 & Interesting & 1 & 2 & 3 & 4 & 5 & 6 & 7 \\
\hline 13 & Intimate style & 1 & 2 & 3 & 4 & 5 & 6 & 7 \\
\hline 14 & Got new knowledge & 1 & 2 & 3 & 4 & 5 & 6 & 7 \\
\hline 15 & Got a new perspective & 1 & 2 & 3 & 4 & 5 & 6 & 7 \\
\hline \multicolumn{9}{|c|}{ (Items that have been deleted result of exploratory factor analysis) } \\
\hline 16 & It seems able to explain to others. & 1 & 2 & 3 & 4 & 5 & 6 & 7 \\
\hline
\end{tabular}

Note. $※$ Scores of Item 5 were reversed. 